\title{
Vincent MASSE
}

\section{Constantes et variantes de la figure du Géant}

Ce collectif ne visant pas à couvrir de manière exhaustive la topique du gigantisme à travers les siècles, il serait déloyal d'en décrier les lacunes. Mentionnons néanmoins l'omission des occurrences rabelaisiennes, dont on peut en fait se réjouir, puisque Marianne Closson et Myriam White-Le Goff, en contournant des lieux souvent fréquentés par la critique, ont fait le choix de la diversification plutôt que du ressassement. Il pourrait paraitre vain, en effet, de répéter l'ouvrage que Walter Stephens a consacré à Rabelais et à ses sources (Giants in Those Days: Folklore, Ancient History, and Nationalism, University of Nebraska Press, 1989) et qui vient d'être traduit en français par Florian Preisig (Honoré Champion, 2006). Malgré le parti pris d'éclectisme des auteurs, l'introduction réussit à exposer des idées et des enjeux clairs sur la question et rend bien compte des approches chronologique et thématique privilégiées par les auteurs du collectif. Des premières mythologies — gigantomachie gréco-romaine et genèse biblique - et de sa péjoration médiévale jusqu’à sa réhabilitation $\left(\mathrm{XV}^{\mathrm{c}}\right.$ et $\mathrm{XVI}^{\mathrm{e}}$ siècles) et à son instrumentalisation en métaphores poétique, politique et nostalgique, on y rencontre le Géant comme signe d'altérité, de sauvagerie originelle, élémentaire et organique, ou comme rescapé d'un monde ancien, disparu ou en voie de l'être.

Au contraire de nombreux recueils d'études thématiques préoccupés par la contemporanéité, on s'intéresse ici à la longue durée : onze contributions couvrent une période allant de l'herméneutique des Pères de l'Église aux géants désacralisés, «encourtisanisés » du XVII siècle; sept se vouent aux nostalgiques $\mathrm{XIX}^{\mathrm{e}}$ et $\mathrm{XX}^{\mathrm{e}}$ siècles. Entre les deux : un trou de la taille du XVIII ${ }^{\mathrm{e}}$ siècle.

Jean-Marc Vercruysse ouvre la discussion, en abordant l'herméneutique des Pères de l'Église, des géants du texte biblique, particulièrement ceux des versets Gn 6,1-4, dont le laconisme a engendré nombre de débats théologiques et exégétiques et qui 
intéressent le rapport humain/divin, l'histoire providentielle, la morale, et le rapprochement du christianisme et de la mythologie grecque. Jean Céard - qui signe la contribution suivante - soutenait en 1978, dans un article devenu canonique, que les discussions relatives à l'existence des géants sont liées au problème du vieillissement ou de l'éternité du monde ("La querelle des Géants et la jeunesse du monde », The Journal of Medieval and Renaissance Studies, 1978, vol. VIII, n 1, p. 37-76). Il complète sa réflexion d'alors en proposant cette fois une lecture de la Dissertation sur les Geans de Dom Augustin Calmet (1720), qui prête à la Bible un sens littéral : les Géants ont bien existé et les fables païennes ne font que mythifier cette vérité, par ailleurs démontrée par la découverte d'ossements. Il n'en rejette pas moins la thèse lucrétienne de l'épuisement progressif du monde: leur disparition s'explique plutôt par la chasse et les variations de fécondité.

Olivier Szerwiniack, à travers une lecture de la Description de l'Irlande de Giraud de Barri (XII ${ }^{\text {e }}$ siècle) et de ses sources (notamment les Étymologies d'Isidore de Séville), expose une acception médiévale du géant défini par son enfantement par l'élément terrestre plutôt que par sa taille: les géants Fomóires, habitants primordiaux de l'Irlande, y «apparaissent comme des émanations personnifiées de la terre qui se venge contre ses agresseurs ». Le géant "pré-humain, inférieur à l'humain, symbolique de la préhistoire », apparaît également dans la lecture du roman Perceforest (XIV ${ }^{\mathrm{e}}$ siècle) qu'offre Catherine Rollier. Pourtant, plus qu'une simple épreuve épique adressée au héros chevalier, cet envers de l'homme est également son miroir, et le personnage du Géant ou de la Géante peut alors s'accompagner d'un effet comique. Sophie Albert s'intéresse également au Perceforest: le héros chevalier, tuant le Géant et libérant la terre et la femme de ce dernier, entreprend de civiliser les lieux et d'humaniser la Géante et sa fille, dont les descendants réapparaittront dans le cycle de la quête du Graal. Figure de l'altérité en demande de domestication, le Géant surgit ensuite, au tournant du $\mathrm{XVI}^{\mathrm{e}}$ siècle, dans l'Amérique vue par l'Europe, qui se peuple de géants pratiquant le cannibalisme et la sodomie; Nicolas Balutet en suit la progression, de 1553 à 1644, et le géant y apparaît comme un monstre contre-nature, bouc émissaire porteur de peurs sociales, exemplum salutaire adressé aux fidèles et 
argument de conquête.

$\mathrm{Au} \mathrm{XVII}$ siècle, ainsi que l'expose Marie-Agnès Thirard, Madame d'Aulnoy est l'initiatrice d'une mode du récit féerique, récupérant l'Ogre des contes populaires et le Géant de la mythologie savante en un amalgame digestible aux lecteurs de la cour de Versailles. Cette transmutation mondaine affecte principalement la Géante, personnage coquet, voire libertin, autrement plus évolué que son homologue masculin, resté bête et méchant. Retour au siècle précédent: AnnePascale Pouey-Mounou présente l'«écrabouillement de cervelle » appliquée, dans l'œuvre de Pierre de Ronsard, aux révoltés de la gigantomachie; cette image épique mêle la violence héroïque à l'horreur et le Géant y est « représentant d'un imaginaire de l'informe qu'il partage avec les Cyclopes, les monstres et les mollusques », et qui illustre la verticalité rabaissée et la résurgence cyclique du chaos. Au contraire d'une esthétique antiquisante, le Géant dans l'œuvre de Charles Sorel, écrit Cécile Cerf-Michaut, est représentatif, à travers les romans de chevalerie, d'une " petite littérature», voire d'une «mauvaise littérature » pourtant plaisante : «la qualité littéraire des romans serait inversement proportionnelle à la taille de leurs protagonistes ». Cela n'empêche pas l'apparition du personnage et son emploi comme support à une «réflexion linguistique, sur la transcription du réel, le style, le plaisir du lecteur et de l'auteur ».

Sébastien Mullier analyse la présence de la géante dans la poésie de Baudelaire, figure qui réunit érotique et plastique afin de symboliser une démarche esthétique de circonscription de l'illimité : "enclore "l'infini dans le fini" pourrait être la formule même de la poétique de Baudelaire ». Même personnage, autre emploi : si La Boétie, dans son Discours de la servitude volontaire, recourt à la figure du Géant pour désigner le Tyran, ce n'est pas afin de perpétuer l'illusion de son pouvoir, explique Alexandre Tarrête, mais plutôt afin d'en démontrer les faiblesses cachées; telle la statue creuse du Colosse de Rhodes ou le géant aux pieds d'argile du prophète Daniel, le Tyran est «toujours près de basculer». L'image du colosse anthropophage et «mangepeuple » jeté à bas connaîtra un grand succès chez les polémistes réformés des guerres de Religion. 
Claudine Nédélec livre l'une des contributions les plus intéressantes du collectif, quoiqu'un peu rapide: à l'aide de trois corpus a priori disparates - querelle de 1613-1618 autour de la découverte d'os gigantesques; mazarinades; travestissements liés au mythe antique de la gigantomachie -, elle démontre une désacralisation et une instrumentalisation constantes du Géant à travers les sciences objectives naissantes, le pamphlet politique et la dévalorisation burlesque. Pourtant, grâce à son esthétisation dans les gravures et les sculptures, la perte de la dimension proprement mythique du Géant n'est pas complète.

Le $\mathrm{XIX}^{\mathrm{e}}$ siècle fournit des exemples d'usage du Géant personnifiant les acteurs et les forces historiques. Ainsi que le montre Julie Anselmini, dans les romans historiques d'Alexandre Dumas peignant la Révolution, le Géant prend une dimension populaire, en s'associant aux héros révolutionnaires et au peuple lui-même, géant dans sa multitude, robuste, sain et naturel face à la délicatesse et à la pâleur aristocratiques. Conducteur d'épique et de merveilleux, le Géant est une force cosmique démontrant la nécessité de la Révolution et exonérant la violence des particuliers. Anne-Sophie Morel expose, quant à elle, la contribution de Chateaubriand à la figuration de Napoléon en géant, illustrant ainsi tant la grandeur de ses succès et la violence de sa chute que son despotisme : à travers la conscription, il erre tel un ogre, affamé de jeunes hommes pour ses guerres. Malgré ces griefs, l'image du Géant pare l'Empereur de grandeur ainsi que de démesure, et l'oppose à la médiocrité d'un présent prosaïque, d'où l'héroïsme a fui. Nostalgie que l'on retrouvera au $\mathrm{XX}^{\mathrm{e}}$ siècle : Jaël Grave, à travers l'œuvre de Samivel, livre en effet un portrait de derniers géants, gardiens montagnards et mythiques du sacré, repoussés vers l'imaginaire par l'urbanisation progressive, le tourisme, etc. Pourtant, explique Anne Besson, le Géant se fait rare en fantasy actuelle, genre «d'essence nostalgique » où pullulent néanmoins les Nains; cet effacement pourrait être imputé à l'œuvre de J. R. R. Tolkien, à travers laquelle lui survivent néanmoins des cousins : l'Ent végétal et le Troll minéral. C'est principalement en fantasy pour la jeunesse et en réécritures arthuriennes qu'on le retrouve, mêlé 
d'Homme Sauvage médiéval, survivant stéréotypé d’ères révolues.

Mais le Géant, au $\mathrm{XX}^{\mathrm{e}}$ siècle, n’est pas simplement un « dernier refuge contre une modernité amoindrie ou comme expression de la nostalgie d'une littérature ancienne » : au contraire - ainsi que le suggère Isabelle Roussel-Gillet par sa lecture de l'imaginaire de J. M. G. Le Clézio -, il est susceptible de participer aux bouleversements de la modernité. Et susceptible de réécritures, évidemment: le collectif se clôt sur une lecture, par Isabelle Dangy, du Vaillant petit tailleur, roman d'Éric Chevillard (2003), "réécriture distanciée » du conte de Grimm où se mêlent démolition du genre du conte et, grâce au Géant, émergence de la figure de l'écrivain.

Rares sont les chercheurs qui s'intéresseront à la totalité de l'ouvrage, mais rare également celui qui ne trouvera pas son profit d'une ou d'une autre contribution. La piètre qualité matérielle de l'ouvrage invite d'ailleurs à la lecture décousue, puisque ses pages tombent rapidement d'entre les mains...

Référence : Marianne Closson et Myriam White-Le Goff (dir.), Les Géants entre mythe et littérature, Artois Presses Université, 2007, 240 p. 